\title{
Analysis of total carbon emission of the logistics industry in Guangdong and solutions to emission reduction
}

\author{
Aixia $\mathrm{Xu}^{1, *}$, Xiaoyong Yang ${ }^{2}$ \\ ${ }^{1}$ Software Engineering Institute of Guangzhou, Guangzhou, China \\ ${ }^{2}$ Zhujiang College, South China Agricultural University, Guangzhou, China
}

\begin{abstract}
The input-output method is employed in this study to measure the total carbon emission of the logistics industry in Guangdong. The findings revealed that the carbon emission of direct energy consumption of the logistics industry in Guangdong is far above the actual carbon emissions, the second and third industries play a significant role in carbon emission of indirect energy consumption in the logistics industry in Guangdong. To reduce energy consumption and carbon emissions in Guangdong, it is not only important to control the carbon emissions in the logistics industry, but strengthen carbon emission detection in relevant industries, improve the energy utilization rate and reduce emissions in other industries, and move towards low-carbon sustainable development.
\end{abstract}

\section{INTRODUCTION}

Aside from input of labor and capital, social activities also consume energies and other natural resources, and meanwhile emit or discharge wastes to the environment. Economic activities have close connections with the natural environment: the culture and economic policies affect the environment, and the environmental policies are likely to restrict economic growth and affect demographic and social shifts. Thus, economy and the environment are two interactive aspects that comprise an organic whole [1].

Under the pressure of energy shortage and ecological threats, green development turns the only way out. Guangdong, the major force for construction of the Guangdong-Hong Kong- Macau Greater Bay Area, assumes a leading role in the initiatives to reduce carbon emissions. In 2017 , the logistics industry consumes $11.16 \%$ of the total energy in Guangdong, only $4.3 \%$ less than the energy consumption by daily life which ranks the second. It reveals the gap that the logistics industry in Guangdong has with the national average level and the great pressure the industry faces in reducing carbon emissions. These statistics are obtained based on the direct energy consumption of the logistics industry, and the indirect energy consumed by the logistics industry through the intermediate products produced by other sectors is excluded. Currently, the division of responsibilities for carbon emission follows the "production-oriented principle", which is impractical because of the close correlation the logistics industry has with other industries. To identify the responsibilities of carbon emission reduction in a more scientific manner, we need to not only consider the direct energy consumption of industries and enterprises, but take into account the indirect energy consumption. Only in this way can we measure energy consumption in an all-round manner, and thereby identify the responsibilities of carbon emission reduction, allocate the emission quotas, and assess the emission reduction performance in a scientific way.

\section{RESEARCH STATUS QUO}

There has been much research devoted to the correlation between economy and energy consumption, and the inputoutput model has been an effective tool for quantitative analysis. Since it was proposed by Leontief in 1936, the input-output model has been developed for more than eighty years, seeing wide adoption not only in economic development strategy-making, gross scale measurement, development speed calculation and economic restructuring, but also in environmental protection and green house gas emission. The latter has become a focus of application of the input-output method. Machado et al. (2001) employed the input-output method and achieved the conclusion that developed countries have transferred carbon emissions to developing countries by outsourcing and importing finished products [2]. Mathews et al. (2008) measured the direct carbon emission and total carbon emission by the input-output method [3]. Lutter et al. (2016) analyzed the advantages of the input-output method in carbon emission analysis [4]. In existing English publications, the application of the input-output model in the environment and energy field is principally on the impact of implicit carbon in trading on the environment and the final energy consumption on the environment.

Compared with studies abroad, domestic studies that applied the input-output model on quantitative analysis of carbon emissions started later. Since 2008, many scholars have applied the input-output model to research on

* Corresponding author: 330649189@qq.com 
implicit carbon emissions in China's global trading, but studies that focused on the indirect carbon emissions from one specific industry or product are rare. Some Chinese scholars such as Ye (2011) [5], Zhang and Liu (2013) [6], Yuan (2013) [7], Tan and Tan (2016) [8], Wang and Liu (2018) [9] measured and analyzed the carbon emissions of Chinese residents' consumption, the construction industry, the tourism industry, the transport industry in Beijing and China's logistics industry respectively.

Review of domestic literature shows that application of the input-output model to indirect carbon emission focused on household consumption, the construction industry, tourism, and international trading, but studies that focused on the logistics industry are rare. Therefore, this study analyzed the input-output data in Guangdong from 2002 to 2017, and employed the input-output method to measure the total carbon emissions of the logistics industry in Guangdong, with a vision to provide a basis for energy conservation and emission reduction of the logistics industry in Guangdong.

\section{Measuring method and data source}

\subsection{Measuring method of carbon emissions of the logistics industry}

\subsubsection{Measuring method of indirect carbon emission}

The universal method of measuring the direct carbon emissions of the logistics industry is to multiply the activity level of energy consumption by the corresponding carbon dioxide emission factor [10]. As shown in The Annual Statistical Report of Energy Consumption of China, the logistics industry mainly consumes 11 types of energies including coal, petroleum, and diesel. Thermal power and electric power are secondary energies, the production of which will consume raw coal and briquette coal, so these secondary energies have a different carbon emission factor from other energies. The carbon emission factor of these energies can be calculated by the standards released by the administrations, but the consumption of primary energies is the real consumption statistics, and should be converted to data by the unit of standard coal. Table 1 shows the relevant factors.

Based on previous studies, we obtain the calculation equation for the direct carbon emission of the logistics industry:

$$
D C=\sum E_{i 1} \cdot F_{i 1} \cdot C_{i 1}+\sum E_{j 2} \cdot C_{j 2}
$$

Where $D C$ is the direct carbon emission of the logistics industry, $E_{i 1}$ is the consumption volume of the i-th primary energy, $E_{j 2}$ is the consumption volume of the $\mathrm{j}$-th secondary energy, $F_{i 1}$ is the standard-coal carbon-emission factor of the $\mathrm{i}$-th primary energy, $C_{i 1}$ is the carbon emission factor of the i-th primary energy, and $C_{j 2}$ is the carbon emission factor of the j-th secondary energy.
Table 1. Conversion factors $F_{i}$ from physical units to coal equivalent and the $\mathrm{CO}_{2}$ emission factors $C_{i}$ [11].

\begin{tabular}{cccc}
\hline $\begin{array}{c}\text { Serial } \\
\text { number }\end{array}$ & Energy & $\begin{array}{c}F_{i} \\
(\mathrm{kgce} / \mathrm{kg})\end{array}$ & $\begin{array}{c}C_{i}\left(\mathrm{t} \mathrm{CO}_{2} / \mathrm{t}\right. \\
\mathrm{ce})\end{array}$ \\
\hline 1 & Raw Coal & 0.7143 & 0.7559 \\
2 & Gasoline & 1.4714 & 0.5538 \\
3 & Kerosene & 1.4714 & 0.5714 \\
4 & Diesel Oil & 1.4571 & 0.5921 \\
5 & Fuel Oil & 1.4286 & 0.6185 \\
6 & LPG & 1.7143 & 0.5042 \\
7 & Natural & $1.33 \mathrm{kgce} / \mathrm{m}^{3}$ & 0.4483 \\
& Gas & & $0.11 \mathrm{t} \mathrm{CO} 2$ \\
8 & Heat & - & $/ \mathrm{GJ}^{2}$ \\
& & & $0.5271 \mathrm{t}$ \\
9 & Electricity & - & $\mathrm{CO}_{2} / 10^{3}$ \\
& & & $\mathrm{kWh}$ \\
\hline
\end{tabular}

Note: $F_{i}$ is from the national standard "Comprehensive Energy Consumption Calculation Code" (GB/T 2589-2008), the $C_{i}$ of heat is the default value of carbon emission factor of heat in the green-house gas calculation guide released by the National Development and Reform Commission, and the $C_{i}$ of electric power is the mean value of $C_{i}$ of regional power grid released by the National Development and Reform Commission in 2012; the $C_{i}$ of other energies is the default emission factor specified in 2006 IPCC National Green-house Gas List Guideline.

\subsubsection{Carbon emission measurement based on the input-output method}

(1) Parameters

1) Carbon intensity

$$
C_{i}=\frac{D C_{i}}{X_{i}}
$$

Where $C_{i}$ is the carbon intensity of the i-th sector, $D C_{i}$ is the direct carbon emission of the $\mathrm{i}$-th sector, and $X_{i}$ is the total output of the i-th sector.

2) Direct consumption factor matrix

$$
A=\left(a_{i j}\right)_{n \times n^{\prime}}(i, j=1,2,3, \cdots, n)
$$

Where $a_{i j}=\frac{z_{i j}}{X_{j}}$ refers to the direct consumption coefficient of the production unit of the $\mathrm{j}$-th sector to the $\mathrm{i}$-th sector, $Z_{i j}$ is the direct consumption volume of the $\mathrm{j}$ th sector to the i-th sector, and $X_{j}$ is the total input of the j-th sector.

3) Total consumption coefficient matrix

$Y=(E-A)^{-1}-E=\left(y_{i j}\right)_{n \times n},(i, j=1,2,3, \cdots, n)$

Where $Y$ is the total consumption coefficient matrix, $y_{i j}$ stands for the number of products produced by the ith sector consumed by the $\mathrm{j}$-th sector.

$B=(E-A)^{-1}=\left(b_{i j}\right)_{n \times n},(i, j=1,2,3, \cdots, n)$ is a total demand coefficient matrix, also termed the Leontief inverse matrix, $b_{i j}$ represents full demand of the $\mathrm{j}$-th sector for the i-th sector when producing one unit of products.

(2) Measuring method of total carbon emission of the logistics industry

Step 1: calculating the direct carbon emission volume $D C_{i}$ of each industry in Guangdong as per Eq. (1);

Step 2: calculating the carbon intensity $C_{i}$ of each industry as per Eq. (2); 
Step 3: calculating the total consumption coefficient $y_{i}$ of the logistics industry to other industries as per Eqs. (3) and (4);

Step 4: Calculating the indirect carbon emission of the logistics industry:

$$
\text { IC }=\sum C_{i} \cdot y_{i} \cdot X
$$

Step 5: Calculating the total carbon emission of the logistics industry, which is the sum of the direct carbon emission and the indirect carbon emission:

$$
T C=D C+I C
$$

or

$$
T C=\sum C_{i} \cdot b_{i} \cdot X
$$

where $b_{i}$ is the Leontief inverse coefficient of the logistics industry to other industries.

\subsection{Data source}

The input and output data used in this paper are from the 2002 - 2017 Input-output Table (Extended) released on the website of stats.gd.gv.cn; the energy consumption data are from the China Energy Consumption Statistics Annual
Book and the Annual Book of Statistics of Guangdong. As the logistics industry has not been singled out in the existing statistics, and relevant data about logistics fall into categories of "transportation, storage and postal services", which are regarded as the logistics industry in this paper. To facilitate calculation, the 42 industries listed in the Input-output Table (Extended) are integrated into the 7 industries listed in the Energy Consumption Year Book of China, among which the "other third industries" include information transmission, real estate and household services.

\section{Analysis of total carbon emission by the logistics industry in Guangdong}

\subsection{Direct carbon emission}

As per Table 1 and Eq. (1), we can obtain the direct carbon emission of the logistics industry of Guangdong. The result is shown in Table 2.

Table 2. The direct $\mathrm{CO}_{2}$ emission volumes of the logistics industry in Guangdong Province from 2002 to 2017. (Measurement unit: ten thousand tons)

\begin{tabular}{cccccccc}
\hline Energy & 2002 & 2005 & 2007 & 2010 & 2012 & 2015 & 2017 \\
\hline Raw Coal & 0.73 & 0.76 & 0.90 & 1.10 & 1.31 & 2.39 & 2.52 \\
Gasoline & 179.46 & 304.01 & 362.59 & 442.86 & 487.48 & 328.18 & 417.80 \\
Kerosene & 82.31 & 120.23 & 133.51 & 163.08 & 194.18 & 223.75 & 245.75 \\
Diesel Oil & 291.55 & 530.93 & 580.68 & 720.15 & 781.27 & 900.25 & 958.44 \\
Fuel Oil & 52.97 & 7.14 & 78.21 & 104.36 & 113.74 & 152.49 & 204.41 \\
LPG & 0.00 & 26.39 & 31.47 & 35.46 & 0.00 & 42.03 & 44.29 \\
Natural Gas & 0.00 & 0.00 & 0.00 & 1.17 & 0.00 & 1.84 & 1.93 \\
Heat & 0.00 & 0.00 & 0.00 & 0.00 & 0.00 & 0.29 & 0.32 \\
Electricity & 146.80 & 160.45 & 196.29 & 286.74 & 359.01 & 434.44 & 576.96 \\
Total & 753.82 & 1149.90 & 1383.65 & 1754.92 & 1936.99 & 2085.65 & 2452.43 \\
\hline
\end{tabular}

As Table 2 shows, the direct carbon emission of the logistics industry in Guangdong increased by $225.33 \%$ from 2002 to 2017 , with an annual growth rate of $21.73 \%$ and a decreasing comparative growth rate.

As new energies are developed and more widely utilized in China, the consumption of natural gas and electricity by the logistics industry in Guangdong increases. Recent statistics show that the carbon emission caused by consumption of electricity rose from $18.53 \%$ in 2012 to $25.53 \%$ in 2017 in the total carbon emission; the carbon emission caused by consumption of petroleum dropped from $25.17 \%$ in 2012 to $17.14 \%$ in 2017 in the total carbon emission. This finding reveals that since China became the one of the first pilot province for carbon trading in 2013, the energy consumption structure of the logistics industry in Guangdong changes, but in 2017, the carbon emission caused by consumption of diesel reached a proportion as high as $39.08 \%$, while the proportion of natural gas was merely $0.08 \%$, which suggests that it is necessary to increase the utilization of green energies in the logistics industry in Guangdong.

\subsection{Analysis of carbon emission based on the input-output method}

\subsubsection{Total consumption coefficient}

Table 3 lists the total consumption coefficients of the logistics industry to other relevant industries in Guangdong.

As Table 3 shows, the logistics industry of Guangdong has the largest total consumption coefficient to the second industry, and the coefficients to other industries are far smaller. The third industry ranks the second in this regard, which suggests the strong dependence of the logistics industry on the second and third industries in Guangdong, and a strong correlation between the logistics industry and these two industries. It also shows that these two industries are the major sources of indirect carbon emissions of the logistics industry [11]. 
Table 3. The complete consumption factors of the logistics industry to other industries in Guangdong Province from 2002 to 2017.

\begin{tabular}{ccccccccc}
\hline Sector & 2002 & 2005 & 2007 & 2010 & 2012 & 2015 & 2017 \\
\hline Agriculture,Forestry, Animal & 0.0302 & 0.0252 & 0.0338 & 0.0432 & 0.0329 & 0.0363 & 0.0478 \\
Husbandry and Fishery & 0.9455 & 1.0845 & 1.2519 & 1.4706 & 1.4060 & 1.3890 & 0.8145 \\
$\quad$ Industry & 0.0134 & 0.0059 & 0.0062 & 0.0078 & 0.0032 & 0.0031 & 0.0099 \\
$\quad \begin{array}{c}\text { Construction } \\
\text { Logistics }\end{array}$ & 0.2031 & 0.1481 & 0.1102 & 0.1397 & 0.2232 & 0.2649 & 0.2833 \\
$\begin{array}{c}\text { Wholesale, Retail Trade and } \\
\text { Hotel,Restaurants }\end{array}$ & 0.0946 & 0.0577 & 0.0611 & 0.0617 & 0.0946 & 0.0972 & 0.0911 \\
$\quad$ Athers & 0.2455 & 0.2146 & 0.2291 & 0.2528 & 0.2297 & 0.2544 & 0.3893 \\
$\quad$ Residential Consumption & 0.0080 & 0.0047 & 0.0048 & 0.0082 & 0.0048 & 0.0063 & 0.0162 \\
\hline
\end{tabular}

\subsubsection{Total carbon emission}

Table 4 shows the detailed data of total carbon emission of the logistics industry in Guangdong.

As Table 4 shows, though the carbon emission of the logistics industry of Guangdong has increased as the industry develops, the comparative growth rate has dropped as the central and local governments take measures to protect the environment and reduce emissions. Since 2008, the Guangdong government has initiated energy conservation projects worth 200 million yuan per year, with a vision to boost industrial upgrading by energy conservation and emission reduction measures, and rely on technological progress to improve the utilization of resources [12]. The logistics industry of Guangdong has also adopted a range of measures to reduce emission, such as increasing the proportion of high-efficiency vans, promoting the use of LNG containers, developing large, standardized and professional ships, shifting the power of the wharf from petroleum to electricity, and advancing multimodal transport [13]. The proportions of carbon emissions show that in 2002, the proportion of direct carbon emission is lower than that of indirect emission, but exceeds the latter in 2005 and 2007; in 2010, the proportion of indirect carbon emission grew, which speaks to the achievements that the emission reduction measures have made; nonetheless, more efforts should be made to reduce carbon emissions of relevant industries of the logistics industry.

Table 4. The complete $\mathrm{CO}_{2}$ emission volumes of the logistics industry in Guangdong Province from 2002 to 2017. (Measurement unit: ten thousand tons)

\begin{tabular}{ccccccccc}
\hline Year & $\begin{array}{c}\text { Direct } \mathrm{CO}_{2} \\
\text { emission } \\
\text { volumes }\end{array}$ & $\begin{array}{c}\text { Chain } \\
\text { growth } \\
\text { rates }\end{array}$ & $\begin{array}{c}\text { Ratios to } \\
\text { total } \\
\text { carbon } \\
\text { emission } \\
\text { volumes }\end{array}$ & $\begin{array}{c}\text { Indirect } \mathrm{CO}_{2} \\
\text { emission } \\
\text { volumes }\end{array}$ & $\begin{array}{c}\text { Chain } \\
\text { growth } \\
\text { rates }\end{array}$ & $\begin{array}{c}\text { Ratios to } \\
\text { total } \\
\text { carbon } \\
\text { emission } \\
\text { volumes }\end{array}$ & $\begin{array}{c}\text { Complete } \\
\mathrm{CO}_{2} \\
\text { emission } \\
\text { volumes }\end{array}$ & $\begin{array}{c}\text { Chain } \\
\text { growth } \\
\text { rates }\end{array}$ \\
\hline 2002 & 753.82 & - & $49.27 \%$ & 776.28 & - & $50.73 \%$ & 1530.10 & - \\
2005 & 1149.90 & $52.54 \%$ & $55.15 \%$ & 935.09 & $20.46 \%$ & $44.85 \%$ & 2084.99 & $36.26 \%$ \\
2007 & 1383.65 & $20.33 \%$ & $56.75 \%$ & 1054.36 & $12.75 \%$ & $43.25 \%$ & 2438.01 & $16.93 \%$ \\
2010 & 1754.92 & $26.83 \%$ & $49.64 \%$ & 1780.39 & $68.86 \%$ & $50.36 \%$ & 3535.31 & $45.01 \%$ \\
2012 & 1936.99 & $10.38 \%$ & $46.72 \%$ & 2208.75 & $24.06 \%$ & $53.28 \%$ & 4145.74 & $17.27 \%$ \\
2015 & 2085.65 & $7.67 \%$ & $46.18 \%$ & 2431.10 & $10.07 \%$ & $53.82 \%$ & 4516.75 & $8.95 \%$ \\
2017 & 2452.43 & $17.59 \%$ & $50.71 \%$ & 2383.42 & $-1.96 \%$ & $49.29 \%$ & 4835.85 & $7.06 \%$ \\
\hline
\end{tabular}

\section{Solutions to reduce carbon emissions of the logistics industry in Guangdong}

With economic growth and increased demand for investment, the logistics industry in Guangdong is seeing more refined division of work, which not only extends the industrial chain, but engages more intermediate investment sectors, and thereby causes more indirect carbon emissions. The second industry has long been the object of service of the logistics industry, leading to large carbon emissions of direct and indirect demand of the logistics industry. As the service capacity of the logistics industry to the third industry increases, the carbon emission caused by the increased demand of other third industries to the logistics industry keeps increasing. Therefore, in energy conservation and emission reduction initiatives, the government should not only consider the total carbon emission, but define the responsibilities of emission reduction on different industries, distribute the emission quotas, and assess the performance of emission reduction in a scientific manner. Meanwhile, the government should play a guiding role and the enterprises should be fully engaged to promote the energy utilization efficiency of the logistics industry in Guangdong.

\subsection{Introducing more advanced modern and professional equipment to improve the logistics efficiency}

By phasing out the low-efficiency and energy-intensive vans, backward ships and outdated engineering equipment, the government and logistics enterprises can provide financial subsidies or preferential policies to encourage development of container tractor, drop and pull 
transport vans, create new LNG and high-efficiency ships, and promote technical upgrading of mechanical equipment in ports to restructure the logistics industry, and lift the transportation, warehousing and other logistics equipment to a higher level of modernization and professionalism. It is important to seize on the opportunities of developing the Greater Bay Area to improve logistics infrastructure and informatization of the equipment, upgrade the roads, rails, water courses and ports, make the equipment more intelligent and increase the efficiency of the logistics industry.

\subsection{Reforming the energy utilization ways of the logistics industry}

To meet the needs of logistics at different levels, the government should improve the logistics network, build major logistic links, integrate the road network, waterborne transportation and air flights to create a comprehensive logistics system. More waterborne transport facilities should be developed to give the advantages of water courses of Guangdong full play; vehicles and ships that rely on clean energies should be promoted and supporting facilities should be developed to improve planning of the logistics industry.

\subsection{Improving supervision and service capacity of energy conservation and emission reduction}

The government should not only release incentive policies to encourage logistics enterprises to improve the production technology, adjust the structure of the logistics industry and energy consumption structure, improve the management mechanism of energy conservation and emission reduction. It is also imperative to strengthen detection of carbon emissions of the logistics industry and relevant industries, especially the second industry, engage other industries in energy conservation and emission reduction initiatives, and thereby reaching the goal of low-carbon sustainable development of the logistics industry in Guangdong.

\section{Acknowledgments}

This work is supported by 2017 Project of Specialty Construction of "Logistics Management" in Teaching Quality and Teaching Reform Project of Undergraduate Universities in Guangdong Province ([2017] No. 214 Document of Division of Higher Education, Department of Education, Guangdong Province); Scientific Research Project in South China Institute of Software Engineering, Guangzhou University (ky202029); Project of Scientific Research Team in South China Institute of Software Engineering, Guangzhou University (ST202003).

\section{References}

1. Pang, J. (2016) Energy and environment input-output analysis model: model, method and application. Economic Science Press, Beijing.

2. Machado, G., Schaeffer, R., Worrell, E. (2001) Energy and Carbon Embodied in the International Trade of Brazil: an input-output approach. Ecological Economics, 39:409-424.

3. Matthews, H.S., Hendrickson, C.T., Weber, C.L. (2008) The importance of carbon footprint estimation boundaries. Environmental science \& technology, 42:5839-5842.

4. Lutter, S., Giljum, S., Bruckner, M. (2016) A review and comparative assessment of existing approaches to calculate material footprints. Ecological Economics, 127: 1-10.

5. Ye, Z. (2011) Impact of household consumption in China on carbon dioxide emissions-an analysis based on the carbon emission input-output model. Journal of Statistics and Information, 26: 39-43.

6. Zhang, Z.H., Liu, R.J. (2013) Calculation of carbon emissions of the construction industry based on input-output analysis. Journal of Tsinghua University (Natural Science Edition), 53: 53 - 57.

7. Yuan, Y.J. (2013) Calculation of indirect energy consumption and carbon emissions of the tourism industry in China. Tourism Tribune, 28: 71-80.

8. Tan, Q., Tan, J. (2016) Analysis of the carbon emission characteristics of the transportation industry in Beijing based on the input-output method. Ecological Economy, 10: 73 - 78 .

9. Wang, L.P., Liu, M.H. (2018) Measuring of carbon emission of China's logistics industry and influencing factors based on the input-output method. Resources Science, 40:195-206.

10. Cheng, H. (2014) How to calculate the carbon emission-2006 PICC national green-house gas list guideline. China Statistics, 11: 28-30.

11. Xu, A.X., Ning, Y. (2020) Correlation analysis of $\mathrm{CO}_{2}$ emission in logistics and other industries of China, In: 2nd International Conference on Environmental Prevention and Pollution Control Technologies, EPPCT 2020. Sanya. pp.2-3.

12. Science and Technology in Guangdong. (2008) Chronicle of Major Events of Guangdong Science Center. Guangdong Science, 19: 12-22.

13. Guangdong Provincial Development and Reform Commission. (2017) The 13-th Five-year Plan for energy conservation and emission reduction in Guangdong.

http://www.china-nengyuan.com/news/104412.html 